\title{
ULTRASOUND BIOMICROSCOPIC ASSESSMENT OF ANGLES BEFORE AND AFTER LASER PERIPHERAL IRIDOTOMY IN PRIMARY ANGLE CLOSURE AND PRIMARY ANGLE CLOSURE GLAUCOMA PATIENTS
} \author{
Farook Khan Mohamed Rafi ${ }^{6}$, Shanmugam Rajeswari ${ }^{7}$

\begin{abstract}
${ }^{1}$ Associate Professor, Department of Ophthalmology, Madurai Medical College, Madurai. ${ }_{2}^{2}$ Assistant Professor, Department of Ophthalmology, Madurai Medical College, Madurai. 3Senior Resident, Department of Ophthalmology, Madurai Medical College, Madurai. 4 Junior Resident, Department of Ophthalmology, Madurai Medical College, Madurai. ${ }^{5}$ Senior Resident, Department of Ophthalmology, Madurai Medical College, Madurai. 6Junior Resident, Department of Ophthalmology, Madurai Medical College, Madurai. 7 Junior Resident, Department of Ophthalmology, Madurai Medical College, Madurai.
\end{abstract}

Natarajan Parvathasundari ${ }^{1}$, Essaki Rajeswari2 ${ }^{2}$ Ponnambalam Arunkumar ${ }^{3}$, Selvaraju Sangeetha4, Noorul Hidaya ${ }^{5}$,

\section{BACKGROUND}

ABSTRACT

Acute angle closure glaucoma is a potentially preventable condition and hence early identification and treatment of susceptible patients is of utmost importance. Screening, thus is essential so that timely management can prevent irreversible visual loss. Ultrasound biomicroscopy (UBM) is an imaging modality that has near light microscopic precision for examination of anterior segment.

The aim of this study is to study the angle morphology before and after laser peripheral iridotomy in patients with primary angle closure and primary angle closure glaucoma.

\section{MATERIALS AND METHODS}

This prospective observational study done among 50 patients who fulfilled the inclusion exclusion criteria and consented for the study were adequately evaluated with a complete history, assessment of anterior segment which includes slit lamp examination, gonioscopy by Goldman 3 mirror goniolens, IOP measurement by applanation tonometry, fundus examination using +90D lens and standard automated perimetry. Depending on the clinical findings, the patients were grouped under PAC or PACG. Then Ultrasound biomicroscopic assessment performed by OTI using 35/16 Hz transducer probe was done prior to and 2 weeks after laser peripheral iridotomy.

\section{RESULTS}

Among the 50 patients of study group, 24 had PAC and 26 had PACG. Of the studied population, among PAC group patients 6 were less than 50 years, 16 were between 51 - 60 years and only 2 were above 60 years. Among the PACG group patients, one patient was less than 50 years, 14 were between 51 - 60 years and 11 were more than 60 years. Among the PAC group, $50 \%$ were males and remaining 50\% were females. Among the PACG group, 53.8\% were males and remaining $46.2 \%$ were females. There was an increase in the values of AOD, ACD, TIA, TCPD and ILA. There was a significant decrease in ILCD.

\section{CONCLUSION}

Among the studied population, observation in the angle characteristics showed that there was statistically significant change in the UBM parameters noted in the primary angle closure group; however, in primary angle closure glaucoma no such significant change was noted.

\section{KEYWORDS}

Angle Closure Glaucoma, Biomicroscopy Ultrasound, Gonioscopy.

HOW TO CITE THIS ARTICLE: Parvathasundari N, Rajeswari E, Arunkumar P, et al. Ultrasound biomicroscopic assessment of angles before and after laser peripheral iridotomy in primary angle closure and primary angle closure glaucoma patients. J. Evolution Med. Dent. Sci. 2018;7(05):672-674, DOI: 10.14260/jemds/2018/152

\section{BACKGROUND}

Primary Angle Closure Glaucoma (PACG) is more aggressive and visually debilitating in spite of medical and surgical management.

'Financial or Other Competing Interest': None.

Submission 02-12-2017, Peer Review 12-01-2018,

Acceptance 18-01-2018, Published 29-01-2018.

Corresponding Author:

Dr. Essaki Rajeswari,

Assistant Professor of Ophthalmology,

Eye Department OP No. 50, Government Rajaji Hospital,

No. 1, Panagal Road, Madurai-625020, Tamilnadu.

E-mail: eyedeptgrh@gmail.com

DOI: $10.14260 /$ jemds/2018/152
Acute angle closure glaucoma is a potentially preventable condition and hence early identification and treatment of susceptible patients is of utmost importance. Screening thus is essential, so that timely management can be done to prevent irreversible visual loss. Traditionally, the patient's anterior chamber angle is assessed before and after laser peripheral iridotomy using gonioscope. ${ }^{1}$ However, gonioscopic examination is associated with interobserver bias and does not estimate the angle accurately. ${ }^{2}$

Ultrasound biomicroscopy (UBM) is an imaging modality that has near light microscopic precision for examination of anterior segment. Laser peripheral iridotomy (LPI) has replaced incisional iridectomy for most part, mainly due to its non-invasiveness and safety. ${ }^{3}$ It is indicated for all types of PACG having a component pupillary block and as a 
prophylactic procedure for Primary Angle Closure (PAC) patients with potentially occludable angles. LPI will help in treatment of appositional angle closure by negating pupillary block and thereby reducing the intraocular pressure (IOP). The primary aim of performing a peripheral iridotomy is to relieve pupillary block by creating a hole in the peripheral iris and equalising the intraocular pressure on either side of iris, widening the angle recess and flattening the iris. ${ }^{4}$ Photo disruptive Q-switched Nd: YAG laser is mostly preferred by many surgeons, since it can penetrate and perforate the iris easily.

\section{Aim}

To study the angle morphology before and after laser peripheral iridotomy in patients with primary angle closure and primary angle closure glaucoma.

\section{MATERIALS AND METHODS}

This study was conducted over a period of 8 months in the Department of Ophthalmology, Government Rajaji Hospital, Madurai. A prospective observational study as the clinical diagnosis and procedures used here are the routine procedures followed in our hospital, among patients who fulfilled the inclusion and exclusion criteria and consented for the study. Patients presenting with occludable angles (trabecular meshwork not seen in more than 180 degrees on gonioscopy) with signs of trabecular iris contact such as peripheral anterior synechiae (PAS), raised IOP, lens glaucomflecken, excessive pigmentation on trabecular meshwork, patients presenting with features of PAC or with associated evidence of PACG and patients of age 40 - 70 years were included in our study. Patients in whom angle closure was associated with other ocular causes (lens induced, post vitreoretinal surgery etc.) and age less than 40 years or more than 70 years were excluded from our study. The sample size 50 was calculated based on the reference of SUP TIA pre- and post-LPI mean (standard deviation) of PACG such as 4.55 (2.45) and 6.12 (3.8) with 90\% power and 95\% confidence interval using the formula: $\mathrm{N}_{\text {pairs }}=\left[\left\{\mathrm{Z}_{1-(\alpha / 2)}+\mathrm{Z}_{1-\beta}\right\}^{2} / \Delta^{2}\right]+\left[\mathrm{Z}^{2}{ }_{1-}\right.$ $(\alpha / 2) / 2]$ and $\Delta=\left(\mu_{2}-\mu_{1}\right) / \sigma$ where $\sigma=(\sigma 1+\sigma 2) / 2 . \mu_{1}$ is pre test mean, $\mu_{2}$ is post test mean, $\sigma_{1}$ is SD in pre test, $\sigma_{2}$ is SD in post test, $\Delta$ is effect size, $\alpha$ is significance level and $1-\beta$ is power.

All the patients were adequately evaluated with a complete history, assessment of anterior segment which includes slit lamp examination, gonioscopy by Goldman 3 mirror goniolens, IOP measurement by applanation tonometry, fundus examination using +90D lens and standard automated perimetry. Depending on the clinical findings, the patients were grouped under PAC or PACG. Then Ultrasound biomicroscopic assessment performed by OTI using $35 / 16 \mathrm{~Hz}$ transducer probe was done prior to and 2 weeks after laser peripheral iridotomy to measure central anterior chamber depth (ACD), angle opening distance (AOD), trabecular iris angle (TIA), the length of iris-lens contact (ILCD) and the irislens angle (ILA). The statistical test Shapiro-Wilk was used to check the normality of each parameter and none of the parameters were normally distributed. Therefore, the nonparametric test called Wilcoxon signed-rank test is used for the comparison of pre- and post-LPI measurements. P value < 0.05 is statistically significant ${ }^{¥}$. The data was analysed with SPSS statistical software package (version 16.0 SPSS Inc. Chicago, USA).

\section{RESULTS}

Among the 50 patients of study group, as per the diagnosis made 24 patients grouped as PAC and 26 as PACG. Of the studied population, among PAC group patients, $6(25 \%)$ were less than 50 years, $16(66.6 \%)$ were between $51-60$ years and only $2(8.3 \%)$ were above 60 years. Among the PACG group patients, $1(3.84 \%)$ patient was less than 50 years, 14 (53.84\%) were between 51 - 60 years and $11(42.3 \%)$ were more than 60 years. Among the PAC group 12 (50\%) were males and remaining $12(50 \%)$ were females. Among the PACG group, $14(53.8 \%)$ were males and remaining 12 $(46.2 \%)$ were females.

Among the PAC group, the average ACD increased from $2.19 \pm 0.037 \mathrm{~mm}$ to $2.32 \pm 0.087 \mathrm{~mm}$, AOD increased from an average of $0.105 \pm 0.001$ to $0.209 \pm 0.004 \mathrm{~mm}$, superior TIA increased from an average of $8.252 \pm 0.157$ to $16.081 \pm 0.23$ degrees, inferior TIA increased from an average of $9.125 \pm$ 0.044 to $16.118 \pm 0.24$ degrees, TCPD increased from an average of $0.744 \pm 0.001$ to $0.819 \pm 0.005 \mathrm{~mm}$, IT increased from an average of $0.477 \pm 0.006$ to $0.487 \pm 0.0014 \mathrm{~mm}$, ILCD decreased from an average of $1.21 \pm 0.045$ to $1.162 \pm 0.015$ $\mathrm{mm}$ and ILA increased from an average of $25.72 \pm 0.519$ to $27.754 \pm 0.56 \mathrm{~mm}$; all with $\mathrm{P}$ value of $<0.001$ and statistically significant, Table 1.

In the PACG group, the average ACD increased from 1.65 \pm 0.107 to $1.79 \pm 0.103 \mathrm{~mm}$, AOD increased from an average of $0.063 \pm 0.009$ to $0.076 \pm 0.027 \mathrm{~mm}$. Superior TIA increased from an average of $4.108 \pm 0.85$ to $6.37 \pm 2$ degrees, inferior TIA increased from an average of $4.365 \pm 0.966$ to $6.33 \pm 2.01$ degrees, TCPD increased from an average of $0.655 \pm 0.0181$ to $0.68 \pm 0.027 \mathrm{~mm}$, IT increased from an average of $0.48 \pm$ 0.009 to $0.462 \pm 0.006 \mathrm{~mm}$, ILCD decreased from an average of $1.37 \pm 0.033$ to $1.209 \pm 0.011 \mathrm{~mm}$ and ILA increased from an average of $8.36 \pm 0.074$ to $8.96 \pm 3.89 \mathrm{~mm}$; all with a $p$ value of $<0.001$ which is statistically significant except for ILA ( $\mathrm{p}$ value is 0.71 , which is $>0.05$ ), Table 2 . There was an increase in the values of AOD, ACD, TIA, TCPD and ILA. There was a significant decrease in ILCD. Among the studied PACG patients, there was no significant change in any of the angle parameters following laser peripheral iridotomy.

\begin{tabular}{|c|c|c|c|c|}
\hline PAC & $\mathbf{N}$ & $\begin{array}{c}\text { Pre-LPI } \\
\text { Median } \\
\text { (Interquartile } \\
\text { Range) }\end{array}$ & $\begin{array}{c}\text { Post-LPI } \\
\text { Median } \\
\text { (Interquartile } \\
\text { Range) }\end{array}$ & $\begin{array}{c}P \text { - } \\
\text { value }\end{array}$ \\
\hline $\mathrm{CD}(\mathrm{mm})$ & 24 & $2.2(2.18-2.2)$ & $2.3(2.3-2.32)$ & 0.001 \\
\hline $\begin{array}{l}\text { AOD } 500 \\
(\mathrm{~mm})\end{array}$ & 24 & $\begin{array}{c}0.106 \\
(0.105-0.107)\end{array}$ & $\begin{array}{c}0.213 \\
(0.204-0.213)\end{array}$ & $<0.001$ \\
\hline $\begin{array}{l}\text { SUP TIA } \\
\text { (deg) }\end{array}$ & 24 & $8.3(8.25-8.3)$ & $16.2(16.1-16.2)$ & $<0.001$ \\
\hline $\begin{array}{l}\text { INF TIA } \\
\text { (deg) }\end{array}$ & 24 & $9.1(9.1-9.15)$ & $16.1(16-16.1)$ & $<0.001$ \\
\hline $\begin{array}{l}\text { TCPD } \\
(\mathrm{mm})\end{array}$ & 24 & $\begin{array}{c}0.744 \\
(0.744-0.745)\end{array}$ & $\begin{array}{c}0.815 \\
(0.815-0.825)\end{array}$ & $<0.001$ \\
\hline IT (mm) & 24 & $\begin{array}{c}0.479 \\
(0.471-0.4835)\end{array}$ & $\begin{array}{c}0.488 \\
(0.486-0.488)\end{array}$ & $<0.001$ \\
\hline $\begin{array}{l}\text { ILCD } \\
(\mathrm{mm})\end{array}$ & 24 & $1.21(1.21-1.21)$ & $\begin{array}{c}1.155 \\
(1.155-1.164)\end{array}$ & $<0.001$ \\
\hline ILA (deg) & 24 & $25.3(25.3-26.3)$ & $27.9(27.35-28.2)$ & $<0.001$ \\
\hline \multicolumn{5}{|c|}{$\begin{array}{c}\text { Table 1. Changes in Anterior Chamber Value } \\
\text { after LPI among PAC Group }\end{array}$} \\
\hline
\end{tabular}




\begin{tabular}{|c|c|c|c|c|}
\hline PACG & $\mathbf{N}$ & $\begin{array}{c}\text { Pre-LPI } \\
\text { Median } \\
\text { (Interquartile } \\
\text { Range) } \\
\end{array}$ & $\begin{array}{c}\text { Post-LPI } \\
\text { Median } \\
\text { (Interquartile } \\
\text { Range) } \\
\end{array}$ & $\begin{array}{c}P \text { - } \\
\text { value }\end{array}$ \\
\hline $\mathrm{ACD}(\mathrm{mm})$ & 26 & $1.632(1.63-1.65)$ & $1.78(1.78-1.79)$ & 0.001 \\
\hline $\begin{array}{c}\begin{array}{c}\text { AOD 500 } \\
(\mathrm{mm})\end{array} \\
\end{array}$ & 26 & $\begin{array}{c}0.062 \\
(0.06-0.062) \\
\end{array}$ & $0.071(0.07-0.71)$ & $<0.001$ \\
\hline $\begin{array}{l}\text { SUP TIA } \\
\text { (deg) }\end{array}$ & 26 & $3.895(3.89-4.1)$ & $6(6-6)$ & $<0.001$ \\
\hline $\begin{array}{l}\text { INF TIA } \\
\text { (deg) }\end{array}$ & 26 & $4.2(4.19-4.2)$ & $6.1(5.8-6.1)$ & $<0.001$ \\
\hline $\begin{array}{l}\text { TCPD } \\
(\mathrm{mm})\end{array}$ & 26 & $\begin{array}{c}0.651 \\
(0.651-0.652) \\
\end{array}$ & $\begin{array}{c}0.677 \\
(0.677-0.677) \\
\end{array}$ & $<0.001$ \\
\hline IT (mm) & 26 & $0.48(0.48-0.48)$ & $0.46(0.46-0.46)$ & $<0.001$ \\
\hline ILCD (mm) & 26 & $\begin{array}{c}1.381 \\
(1.38-1.381) \\
\end{array}$ & $\begin{array}{c}1.213 \\
(1.213-1.213)\end{array}$ & $<0.001$ \\
\hline ILA (deg) & 26 & $8.39(8.39-8.4)$ & 7.95 (7.9-9.1) & 0.71 \\
\hline
\end{tabular}

\section{DISCUSSION}

Primary angle closure glaucoma has a significantly high incidence and is half of all adult primary glaucoma has seen in India. The development of PAC to PACG can be prevented by performing an LPI. In eyes with PAC, an LPI may help in reversing appositional angle closure towards controlling IOP. Though laser peripheral iridotomy is being routinely done for all cases of angle closure disease, there are very few studies that have established the exact changes that occur following LPI in PACG. UBM is a high-resolution imaging of anterior segment. It allows objective method of evaluation of angle morphology and is also reproducible. It gives two dimensional gray scale images with a depth of penetration of about $5 \mathrm{~mm}$ and hence the structures from the conjunctiva, cornea, anterior chamber angle, iris, ciliary body, anterior layers of lens zonules and pars plana can be visualised. It also allows quantitative analyses of angle relationships using various parameters that can be saved for future comparison.

In our study group, there was equal number of females and males. This may be attributed to small study group. Among the age distribution, there was a higher number $(60 \%)$ of primary angle closure disease in the age group of 51-60 years. Multiple studies have demonstrated that the incidence of PACD increases with age. LPI leads to a widening of the anterior chamber angle and a deepening of the anterior chamber in eyes with PAC. It does not significantly change any anterior segment parameters in eyes with PACG. In our study, there was a significant increase in ACD among the primary angle closure patients following iridotomy. There was a significant decrease in the thickness of iris and also iridolenticular contact distance in our study. This demonstrates the usefulness of UBM in angle morphology assessment. The effectiveness of laser peripheral iridotomy in primary angle closure has been established; hence, early institution of LPI is essential in primary angle closure disease prior to synechiae formation, the formation of which usually warrants other more invasive modalities like surgery for its correction. Literature says there was a significant change in angle parameters following laser peripheral iridotomy in angle closure suspects. ${ }^{5}$
In a study to evaluate the anterior chamber angle, widening after laser peripheral iridotomy in eyes with PAC and PACG by UBM and gonioscopy concluded that the LPI resulted in significant widening of the anterior chamber angle in the quadrant with LPI and the quadrant furthest away in patients of PACG with established glaucomatous damage. 6

UBM showed these changes better than gonioscopy. In our study, there is a significant change in angle parameters following LPI in PAC patients, but no such change in PACG. This difference may be attributed to the synechial angle closure that occurs in primary angle closure glaucoma patients, which prevents any significant change in the angle configuration following a laser peripheral iridotomy. Thus, timely laser peripheral iridotomy is essential to prevent synechial closure, which may need further medical therapy or invasive surgical procedures.

\section{CONCLUSION}

Among the studied population, observation in the angle characteristics showed that there was statistically significant change in the UBM parameters noted in the primary angle closure group; however, no such significant change was noted in the primary angle closure glaucoma group. Hence, effective strategies should be adopted in order to identify angle closure at an early stage so that they can be treated prior to development of irreversible angle closure glaucoma.

\section{REFERENCES}

[1] Svedbergh B, Alm A, Amér B, et al. Goniodysgenesis in elderly glaucoma and non-glaucoma patients. A masked slit-lamp and gonioscopy study. Acta Ophthalmol (Copenh) 1986;64(1):45-51.

[2] Fleck BW, Wright E, Fairley EA. A randomised prospective comparison of operative peripheral iridectomy and Nd: YAG laser iridotomy treatment of acute angle closure glaucoma. 3 year visual acuity and intraocular pressure control outcome. British Journal of Ophthalmology 1997;81(10):884-8.

[3] Sun X1, Liang YB, Wang NL, et al. Laser peripheral iridotomy with and without iridoplasty for primary angle-closure glaucoma: 1-year results of a randomized pilot study. American Journal of Ophthalmology 2010;150(1):68-73.

[4] Moster MR, Schwartz LW, Spaeth GL, et al. Laser iridectomy: a controlled study comparing argon and neodymium: YAG. Ophthalmology 1986;93(1):20-4.

[5] He M, Friedman DS, Ge J, et al. Laser peripheral iridotomy in primary angle-closure suspects: biometric and gonioscopic outcomes: The Liwan Eye Study. Ophthalmology 2007;114(3):494-500.

[6] Kaushik S, Kumar S, Jain $R$, et al. Ultrasound biomicroscopic quantification of the change in anterior chamber angle following laser peripheral iridotomy in early chronic primary angle closure glaucoma. Eye (Lond) 2007;21(6):735-41. 